T. A. Найденова, E. Н. Новокшонова. Финансово-кредитные инструменты поддержки организаций малого бизнеса в Республике Коми в контексте COVID-19

Научная статья

УДК 336.027

DOI: $10.18101 / 2304-4446-2021-2-55-65$

\title{
ФИНАНСОВО-КРЕДИТНЫЕ ИНСТРУМЕНТЫ ПОДДЕРЖКИ ОРГАНИЗАЦИЙ МАЛОГО БИЗНЕСА В РЕСПУБЛИКЕ КОМИ В КОНТЕКСТЕ COVID-19
}

\author{
(C) Найденова Татьяна Анатольевна \\ кандидат экономических наук, доцент \\ naydenovaTA@mail.ru \\ (C) Новокшонова Елена Николаевна \\ кандидат экономических наук, доцент \\ einai@mail.ru
}

Сыктывкарский государственный университет имени Питирима Сорокина Россия, 167001, г. Сыктывкар, Октябрьский пр-т, 55

\begin{abstract}
Аннотация. Социально-экономические изменения, вызванные пандемией COVID-19, являются существенным вызовом для сектора малого предпринимательства, испытывающего дефицит финансовых ресурсов. В условиях, когда традиционные методы поддержки стали недостаточны, государственные органы власти были вынуждены незамедлительно принимать решения по изменению существующих подходов поддержки малого бизнеса, вводить новые меры обеспечения социальной и экономической стабильности. Целевой установкой статьи является - оценка эффективности антипандемических финансово-кредитных инструментов поддержки малого бизнеса в условиях, сложившихся в связи с ковидным кризисом аномалий. Сделан вывод, что проведение региональных мероприятий наряду с федеральными мерами поддержки субъектов малого бизнеса позволило снизить отрицательные последствия ковидного кризиса. Однако антикризисные программы финансирования и кредитования малого бизнеса по масштабу неадекватны потребностям этого сегмента экономики.
\end{abstract}

Ключевые слова: финансы, финансово-кредитные инструменты, меры государственной поддержки, малый бизнес, пандемия, институты развития

\section{Для цитирования}

Найденова Т. А., Новокшонова Е. Н. Финансово-кредитные инструменты поддержки организаций малого бизнеса в Республике Коми в контексте COVID-19 // Вестник Бурятского государственного университета. Экономика и менеджмент. 2021. № 2. C. 55-65.

\section{Постановка проблемы}

Модель экономической политики России, заточенная на обеспечение экономической безопасности государства, фиксирует в качестве одного из основных постулатов развитие предпринимательства как института, способного успешно преодолеть деструктивную политику сдерживания развития нашей страны со стороны западных партнеров и обеспечить ускорение темпов экономического роста. Однако дальнейшее социально-экономическое развитие страны требует формирования общественного консенсуса по поводу значимости предпринима- 
тельской деятельности как основного фактора экономического развития в условиях рыночной экономики и естественного исчерпания постсоветского научнопроизводственного потенциала [3, с. 2].

Малый бизнес неоспоримо составляет основу национальной экономики и глобального экономического роста, мгновенно фиксирует и отражает проблемные ситуации экономического характера, возникающие в рамках общественных отношений $[9$, с. 123], таким образом, приумножая уровень благосостояния как отдельных субъектов общественных отношений, так всего общества. Малые предприятия создают конкуренцию на рынке, стимулируют появление новых более эффективных и производительных рабочих мест [10, с. 63]. Несмотря на то, что гибкость предприятий малого бизнеса позволяет им оперативно реагировать на изменение внешних условий и полноценно удовлетворять возникающий спрос, они остаются уязвимы перед серьезными экономическими потрясениями из-за невозможности быстрого переформатирования производственных цепочек, бизнес-процессов, а также цепочек формирования добавленной стоимости, когда возникает разрыв международной кооперации всех существующих механизмов, в первую очередь из-за недостаточной финансовой прочности.

Текущая статистика индикаторов, показывающая негативный разворот таких особенно важных на сегодня отраслевых трендов, как конечный спрос, предложение, безработица, реальные располагаемые денежные доходы населения, изменение численности занятых и т. д., отражает практически беспрецедентное ослабление бизнес-иммунитета и критично высокую степень уязвимости всех участников рынка к реалиям текущего пандемического кризиса [1, с. 6]. Дилеммой в России была и остается целесообразность финансовой и нефинансовой поддержки малого бизнеса. Значимость эта тема приобретает в периоды чрезвычайных ситуаций, каковой является ковидный кризис.

В этом контексте перед государством в качестве первоочередной стала задача поиска лучших практик, которые позволили бы малому бизнесу выстоять и приспособиться к новым сложным условиям. Поэтому поддержка малого бизнеса не только традиционно находится в фокусе внимания государственной политики, но и занимает особое место в повестке борьбы с последствиями COVID-19.

Многоаспектность финансовой и нефинансовой помощи со стороны государства малому бизнесу диктует потребность углубления фундаментальных и прикладных исследований формирования необходимых инновационных финансовокредитных инструментов для обеспечения финансирования деятельности, которая осуществляется в рамках экономических отношений государства и конкретного субъекта бизнеса, в частности.

Цель статьи - оценка эффективности антипандемических финансовокредитных инструментов поддержки малого бизнеса в условиях, сложившихся в связи с ковидным кризисом аномалий.

Теория и методология исследования базируются на проработке нормативных документов и отчетов органов государственной власти, отражающих различные аспекты государственной поддержки сектора малого предпринимательства в условиях ограничений в связи с объявленной пандемией. Для реализации поставленной цели использованы методы эмпирического и теоретического познания применяемой модели поддержки сегмента малого бизнеса в России со стороны государства. 
T. A. Найденова, E. Н. Новокшонова. Финансово-кредитные инструменты поддержки организаций малого бизнеса в Республике Коми в контексте COVID-19

\section{Полученные результаты}

Возобновление научных исследований и полемики о роли государства в современной рыночной экономике, необходимости, границах и эффективности государственного финансового вмешательства в экономические и социальные процессы спровоцированы негативным воздействием пандемии коронавирусной инфекции COVID-19. На фоне опасений усиления экономического кризиса в связи с введением вынужденных ограничений возникли «провалы рынка» - ситуация, при которой свободные рынки не в состоянии эффективно распределять ресурсы [8, с. 13]. Поколебалась убежденность в совершенстве парадигмы, построенной в духе экономики предложения, либерализма. Дж. Стиглиц обосновывает положение, в котором за последние два столетия экономисты пришли к признанию того, что рынок не всегда работает так совершенно, как предполагает большинство горячих приверженцев свободного рынка, чему немало примеров [7, c. 67].

На фоне происходящих изменений необходимо государственное вмешательство в экономику исходя из принципов государственного финансового стимулирования экономики при использовании различных финансовых инструментов, таких как налоги и расходы бюджетов. Правительства по всему миру предпринимают беспрецедентные меры поддержки экономики, деловой активности и сохранения занятости. При этом в глобальной перспективе основными субъектами экономической жизни являются не крупные корпорации, а предприятия малого и среднего бизнеса, которые составляют до $90 \%$ всех компаний в мире, обеспечивают $70 \%$ рабочих мест и создают $50 \%$ мирового ВВП. ООН признает обеспечение свободного доступа субъектов малого и среднего предпринимательства к финансовым услугам важным элементом «Повестки-2030», а соответствующие задачи нашли свое отражение в целях устойчивого развития № 8.3 и № $9.3^{1}$.

Международный валютный фонд (МВФ) обозначил четыре основополагающих принципа мер поддержки малого бизнеса²:

- основанность ответных мер на четких целях экономической политики, содействие «осуществлению более общей цели повышения совокупного спроса»;

- установление приоритетности мер, согласующихся с среднесрочными потребностями развития стран: способствовать укреплению программ социальной защиты, либо в контексте расширения охвата, либо в вопросах увеличения размера пособий;

- принятие продуманных компромиссных решений для адресного охвата конкретных предприятий малого бизнеса мерами поддержки, что позволит поддержать наиболее пострадавшие области при определенном объеме расходов и способствовать повышению совокупного спроса;

- согласование мер политики с существующей инфраструктурой с целью ускорения их задействования.

\footnotetext{
${ }^{1}$ Цели в области устойчивого развития. URL: https://www.un.org/sustainabledevelopment/ ru/sustainable-development-goals/ (дата обращения: 27.01.2021). Текст: электронный.

2 Поддержка МСП в контексте COVID-19: Дайджест Департамента международного и регионального сотрудничества СП РФ. 2020. URL: https://docviewer.yandex.ru/ view/0/?*=HECJznYUYVq\%2BFjd7AqtGrV5gm2d7InVybCI6Imh0dHBzOi8vYWNoLmdvdi 5ydS91 (дата обращения: 06.02.2021). Текст: электронный.
} 
В документе «Поддержка компаний государственным сектором» МВФ выделяет несколько аспектов, которые государства должны учитывать при оказании различных форм поддержки:

- ограничение государственного финансирования. Данный фактор влияет на возможный объем поддержки и ее тип. Например, снижение налогов будет отражаться на бюджете сразу, а предоставление гарантий - в будущем;

- административные ресурсы для обеспечения оперативной поддержки;

- эффективность и простота в применении доступных инструментов;

- характеристики компаний-получателей и целевой охват. Например, стоит ли помогать всем малым предприятиям или только предприятиям, в пострадавшей отрасли.

ОЭСР, анализируя меры реагирования стран, отмечает общие тенденции и специфические подходы к оказанию поддержки малым предприятиям, группирует их по блокам ${ }^{1}$ :

- сокращение рабочего времени, временные увольнения и отпуск по болезни;

- отсрочка уплаты налогов, взносов в систему социального обеспечения, платежей по задолженностям, аренде и коммунальным услугам;

- введение, расширение или упрощение предоставления кредитных гарантий для увеличения возможностей коммерческих банков выдавать займы малым предприятиям;

- выдача прямых займов малым предприятиям через государственные институты;

- предоставление грантов и субсидий для компенсации падения доходов;

- реализация структурных мер, помогающих малым предприятиям адаптироваться к новым методам работы и (цифровым) технологиям, найти новые рынки и каналы продаж для продолжения операций, несмотря на ограничительные меры;

- внедрение специальных схем для мониторинга влияния кризиса на малые предприятия и улучшения управления мерами политики, связанными с ними.

Меры поддержки могут оказать существенное влияние на государственный бюджет и уровень долга. По этой причине для обеспечения надлежащего управления принципиально гарантировать прозрачность и независимость сторон при оказании целевой поддержки компаниям. Приведенные в мониторинге цифры демонстрируют, что наибольшее распространение в мире в контексте помощи малого предпринимательства получили инструменты предоставления заемного финансирования, за которыми следуют меры поддержки занятости и налоговые льготы.

\footnotetext{
${ }^{1}$ Поддержка МCП в контексте COVID-19: дайджест Департамента международного и регионального сотрудничества СП РФ. 2020. URL: https://docviewer.yandex.ru/ view/0/?*=HECJznYUYVq\%2BFjd7AqtGrV5gm2d7InVybCI6Imh0dHBzOi8vYWNoLmdvdi 5ydS91 (дата обращения: 06.02.2021). Текст: непосредственный.
} 
T. A. Найденова, E. Н. Новокшонова. Финансово-кредитные инструменты поддержки организаций малого бизнеса в Республике Коми в контексте COVID-19

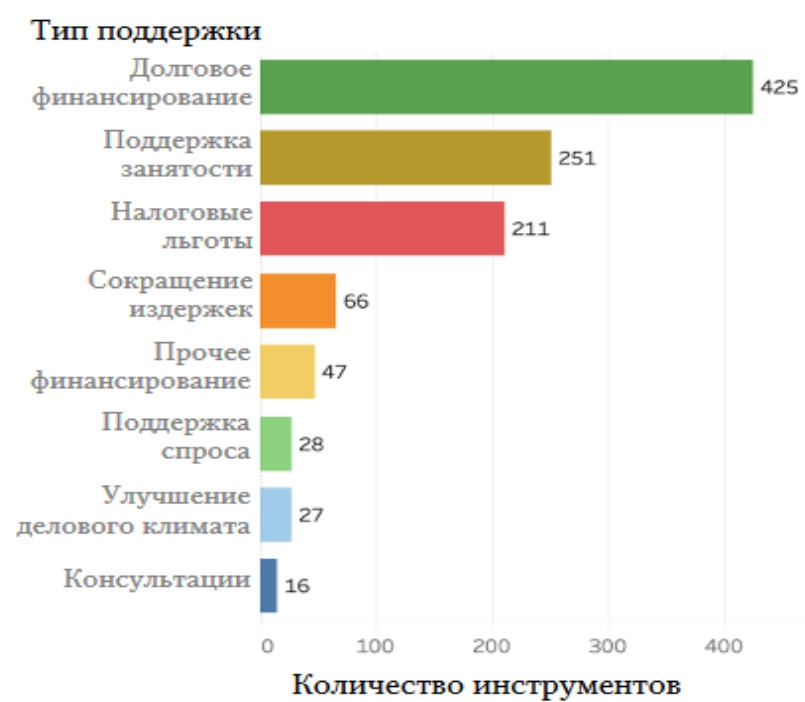

Рис. 1. Инструменты поддержки малого предпринимательства в мире в 2020 г. $^{1}$

В России помощь субъектам малого бизнеса со стороны государства в связи с пандемией инициирована президентом РФ и регламентируется рядом нормативных актов: постановления Правительства от 03.04.2020, 10.04.2020; от 02.04.2020 № 409; от 01.10.2020 №1587; 02.09.2020 №1340; Ф3 от 15.10.2020 №-320. В них утвержден список сфер деятельности, которые несут максимальные убытки из-за распространения COVID-19, и инструменты государственной финансовой и нефинансовой поддержки.

Практика вносит свои коррективы. Антикризисные программы кредитования малого бизнеса по своим масштабам совершенно неадекватны потребностям малых предприятий и неприемлемы для системной поддержки этого сектора и не оказывают существенной поддержки компаниям-заемщикам.

Малым предприятиям, желающим реструктурировать кредит, банки навстречу идут неохотно. Банки либо сознательно, либо просто из-за своего непрофессионализма не наладили антикризисную систему общения со своими клиентами. Естественно, банкиры хотят свои деньги продать подороже с учетом волатильности курса рубля и непонятной экономической ситуации [5]. К тому же банки понимают, что большинство компаний в условиях падения спроса просто не сможет возвратить полученные кредиты. Наращивание финансирования по льготным ставкам позволит сохраниться наиболее конкурентоспособной части малого бизнеса. Основная масса субъектов малого предпринимательства не задумывается о заимствованиях в связи с низкой доходностью. Учитывая сжатие потребительских рынков вследствие снижения доходов населения, удельный вес акторов малого бизнеса в общей сумме выданных кредитов будет редуцироваться. В кон-

\footnotetext{
${ }^{1}$ Поддержка МCП в контексте COVID-19: дайджест Департамента международного и регионального сотрудничества СП РФ. 2020. URL: https://docviewer.yandex.ru/view/ 0/?*=HECJznYUYVq\%2BFjd7AqtGrV5gm2d7InVybCI6Imh0dHBzOi8vYWNoLmdvdi5ydS91 (дата обращения: 06.02.2021). Текст: электронный.
} 
тексте быстро меняющейся экономической ситуации и противоречивой государственной политики множатся опасения невозврата кредита, главным образом в субъектах РФ с недостаточно развитым сектором малого предпринимательства.

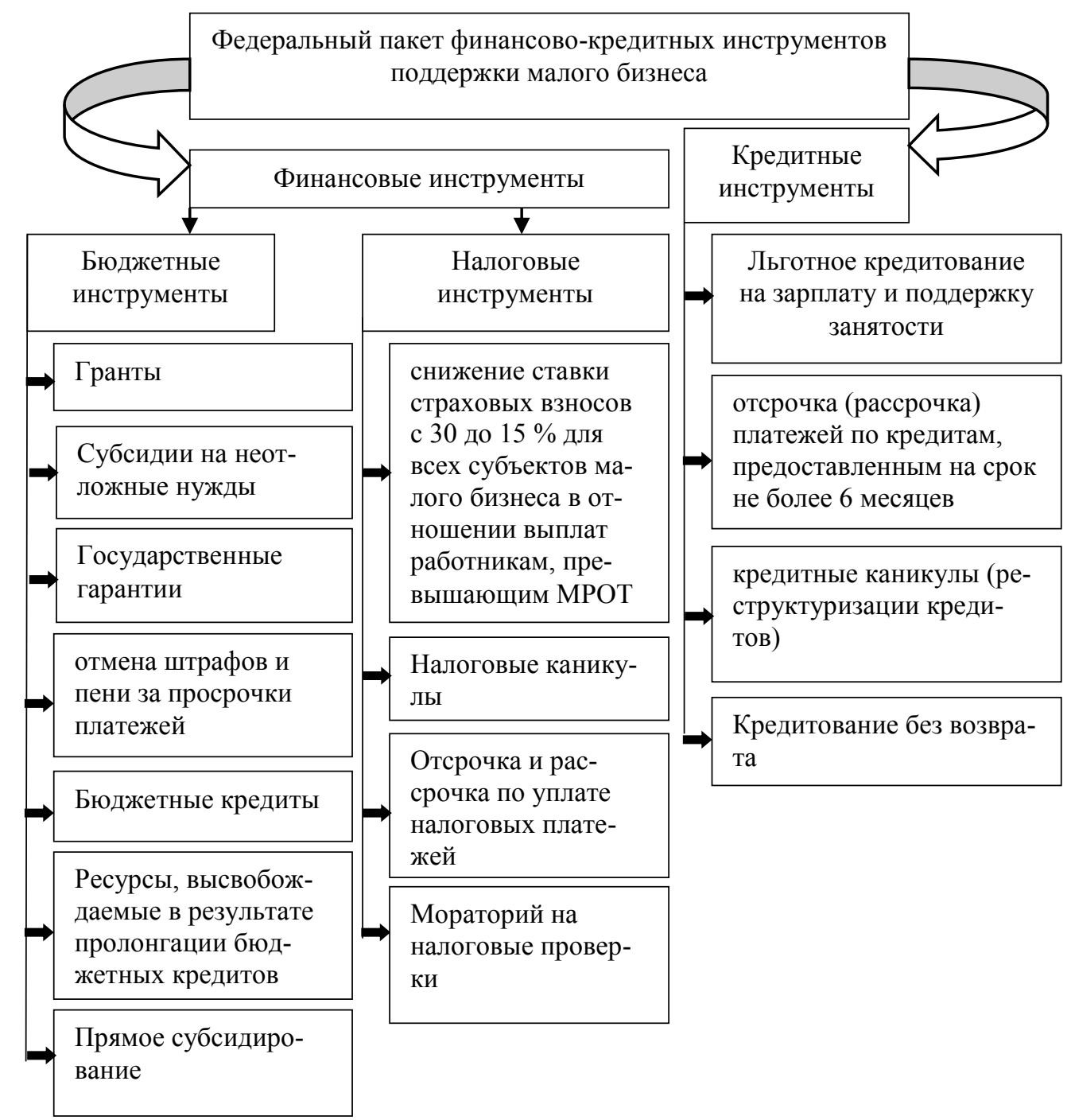

Рис. 2. Финансово-кредитные инициативы федерального центра по поддержке малого бизнеса

Примечание. Прямое субсидирование - это реальные выплаты в размере, определяемом по количеству сотрудников компании и иным критериям. Кредитование без возврата - применение в отношении наиболее пострадавших организаций индивидуальных схем при выдаче кредита. 
T. A. Найденова, E. Н. Новокшонова. Финансово-кредитные инструменты поддержки организаций малого бизнеса в Республике Коми в контексте COVID-19

Что касается налоговых мер поддержки, как перенос сроков уплаты налогов на более поздний срок, налоговые каникулы, то их вообще трудно причислить к мерам поддержки, они никак не сказываются на финансах малого бизнеса. От соблюдения налоговой обязанности, которая является конституционной установкой — платить законно установленные налоги, налогоплательщик не имеет права отказаться. К тому же выполнение обязанности по уплате налога гарантируется возможностью применения к налогоплательщику мер принуждения, предусмотренных законодательством. Таким образом, антипандемические меры поддержки в виде отсроченных обязательств это всего лишь имитация поддержки.

В Республике Коми ситуация менее напряженная, чем в целом по России, поскольку число малых предприятий ниже среднероссийского уровня. Однако последствия пандемии и здесь привели к снижению количества клиентов и выручки у значительного числа малых предприятий.

Исследование детерминант функционирования малого бизнеса в республике в условиях распространения коронавирусной инфекции позволило выявить и утвердить перечень видов деятельности, в большей степени подверженных падению спроса.

Наиболее проблемными секторами оказались ${ }^{1}$ :

1) прочий сухопутный пассажирский транспорт;

2) предоставление мест для временного проживания;

3) предоставление продуктов питания и напитков;

4) предоставление услуг туристическими агентствами и прочими организациями, предоставляющими услуги в сфере туризма;

5) дополнительное образование детей и взрослых;

6) предоставление услуг по дневному уходу за детьми;

7) творческая деятельность в области искусства и организации развлечений;

8) предоставление услуг в области спорта, отдыха и развлечений;

9) ремонт компьютеров, предметов личного потребления и хозяйственнобытового назначения;

10) стирка и химическая чистка текстильных и меховых изделий;

11) предоставление услуг парикмахерскими и салонами красоты.

Ухудшение конъюнктуры во всех обозначенных секторах экономики привело к убыточности, во многих случаях к банкротству организаций малого бизнеса, что и вызвало потребность в государственной финансовой и нефинансовой помощи и поддержке.

В рамках оказания помощи субъектам малого предпринимательства задействован широкий спектр механизмов, предназначенных для нивелирования различных шоков экономики.

Ответом на новые потребности общества являются финансовые институты [2, c. 61]. В Республике Коми реакцией на новые потребности стало задействование системы институтов развития для оказания государственной финансовой поддержки бизнесу в период пандемии: АО «Гарантийный фонд Республики Коми»,

\footnotetext{
${ }^{1}$ Перечень видов деятельности субъектов малого и среднего предпринимательства в Республике Коми, наиболее подверженных падению спроса в условиях распространения коронавирусной инфекции: распоряжение Правительства Республики Коми от 4 апреля 2020 г. № 90-p.
} 
функциональным назначением которого является обеспечение доступа субъектов малого и среднего предпринимательства к кредитным и иным финансовым ресурсам, и АО «Микрокредитная компания Республики Коми», основу функционала которой составляет финансовое сопровождение инвестиционных проектов (табл. 1).

Таблица 1

Инициативы институтов развития в Республике Коми в период пандемии COVID-19 1

\begin{tabular}{|c|c|}
\hline $\begin{array}{c}\text { АО «Гарантийный фонд } \\
\text { Республики Коми» }\end{array}$ & $\begin{array}{c}\mathrm{AO} \text { «Микрокредитная компания } \\
\text { Республики Коми» }\end{array}$ \\
\hline $\begin{array}{l}\text { 1) перенос сроков догово- } \\
\text { ров поручительства по ссу- } \\
\text { дам, реструктуризирован- } \\
\text { ным кредитными организа- } \\
\text { циями на более поздний } \\
\text { срок с уплатой льготного } \\
\text { размера вознаграждения; } \\
\text { 2) снижение размера воз- } \\
\text { награждения (до 0,5\%) за } \\
\text { предоставление поручи- } \\
\text { тельства для отдельных ка- } \\
\text { тегорий получателей }\end{array}$ & $\begin{array}{l}\text { 1) предоставление микрозаймов на льготных условиях в } \\
\text { случае недостаточности залогового обеспечения; } \\
\text { 2) рефинансирование заключенных договоров займа; } \\
\text { 3) перенос сроков уплаты долга на более поздний период; } \\
\text { 4) отмена начисления неустойки при задержке платежей } \\
\text { в погашение микрозайма и уплаты процентов по нему; } \\
\text { 5) привлечение микрозайма на оплату труда работников } \\
\text { и погашение налоговых обязательств; } \\
\text { 6) специальный кредитный продукт под 1\% (требование } \\
\text { - заявитель осуществляет деятельность в одной из от- } \\
\text { раслей, установленных Правилами) }\end{array}$ \\
\hline
\end{tabular}

${ }^{1}$ Источник. Данные официального сайта Министерства экономического развития и промышленности Республики Коми. URL: https://econom.rkomi.ru/. (дата обращения: 10.02.2021). Текст: электронный.

Таблица 2

Характеристика регионального пакета государственной финансовой и нефинансовой поддержки организаций малого бизнеса на территории Республики Коми ${ }^{1}$

\begin{tabular}{|c|c|c|}
\hline Имущественная поддержка & Налоговые льготы & Поддержка сферы ЖКХ \\
\hline $\begin{array}{l}\text { 1) освобождение от арендной } \\
\text { платы акторов малого пред- } \\
\text { принимательства, работаю- } \\
\text { щих в наиболее пострадав- } \\
\text { ших отраслях; } \\
\text { 2) снижение на 50\% аренд- } \\
\text { ной платы для субъектов } \\
\text { МСП, осуществляющих иные } \\
\text { виды деятельности; } \\
\text { 3) отсрочка арендной платы, } \\
\text { её уплата равными частями; } \\
\text { 4) отмена начисления не- } \\
\text { устойки по договорам аренды }\end{array}$ & $\begin{array}{l}\text { 1) введение налога на про- } \\
\text { фессиональный доход; } \\
\text { 2) понижение ставки налога } \\
\text { на имущество организаций до } \\
1 \% \text { на } 2020 \text { г. и } 2 \% \text { на } 2021 \text { и } \\
2022 \text { гг. для субъектов не- } \\
\text { движимости, имеющих ка- } \\
\text { дастровую стоимость; } \\
\text { 3) снижение для субъектов } \\
\text { малого предпринимательства, } \\
\text { работающих на УСНО, став- } \\
\text { ки налога в } 2 \text { раза }\end{array}$ & $\begin{array}{l}\text { 1) приостановление } \\
\text { действия для субъектов } \\
\text { МСП начисления и } \\
\text { взыскания пени за за- } \\
\text { держку оплаты жилищ- } \\
\text { но-коммунальных услуг; } \\
\text { 2) остановка режи- } \\
\text { ма лимитирования по- } \\
\text { требления коммуналь- } \\
\text { ных ресурсов в отноше- } \\
\text { нии субъектов предпри- } \\
\text { нимательской деятель- } \\
\text { ности }\end{array}$ \\
\hline
\end{tabular}

${ }^{1}$ Источник. Данные официального сайта Министерства экономического развития и промышленности Республики Коми. URL: https:/econom.rkomi.ru/. (дата обращения: 10.02.2021). Текст: электронный. 
T. A. Найденова, E. Н. Новокшонова. Финансово-кредитные инструменты поддержки организаций малого бизнеса в Республике Коми в контексте COVID-19

Таблица 3

Федеральные меры государственной финансовой и нефинансовой поддержки организаций малого бизнеса в условиях распространения короновирусной инфекции в Республике Коми ${ }^{1}$

\begin{tabular}{|c|c|c|}
\hline $\begin{array}{c}\text { Страховые } \\
\text { взносы }\end{array}$ & $\begin{array}{c}\text { Сохранение } \\
\text { финансовой стабильности }\end{array}$ & $\begin{array}{c}\text { Снижение } \\
\text { административной нагрузки }\end{array}$ \\
\hline $\begin{array}{lr}\text { снижение } & \text { ставок } \\
\text { страховых } & \text { взно- } \\
\text { сов в два раза для } \\
\text { зарплат } \\
\text { МРОТ }\end{array}$ & $\begin{array}{l}\text { - реструктуризация задолженности; } \\
\text { - отсрочка на погашение остатка ос- } \\
\text { новного долга и процентов; } \\
\text { - приостановка уплаты по кредитам } \\
\text { для отдельных видов экономической } \\
\text { деятельности - } 6 \text { мес.; } \\
\text { - субсидирование отсрочки; } \\
\text { - программа кредитования под } 0 \text { \% } \\
\text { на заработную плату; } \\
\text { - льготный кредит под } 2 \text { \%; } \\
\text { льготное кредитование под } 8,5 \text { \% для } \\
\text { субъектов малого предприниматель- } \\
\text { ства; } \\
\text { - субсидии на возмещение затрат на } \\
\text { профилактику СОVID-19 в соответ- } \\
\text { ствии с Постановлением Правитель- } \\
\text { ства РФ от } 02.07 .2020 \text { № } 576 .\end{array}$ & $\begin{array}{l}\text { мораторий на все проверки; } \\
\text { пролангирование действия } \\
\text { всех лицензий и разрешений } \\
\text { на полгода }\end{array}$ \\
\hline
\end{tabular}

${ }^{1}$ Источник. Данные официального сайта Министерства экономического развития и промышленности Республики Коми. URL: https://econom.rkomi.ru (дата обращения: 10.02.2021). Текст: электронный.

Таким образом, анализ принятых мер показал, что региональные инициативы в условиях пандемии COVID-19 носят по большей части универсальный характер и направлены на предоставление льгот по аренде региональной и муниципальной собственности, региональных налоговых льгот, на снижение кредитной нагрузки на бизнес, поддержку занятости населения и снижение контрольнонадзорной нагрузки [4, с. 165].

Данные меры финансовой помощи, принятые в республике, оказали значительное влияние на состояние субъектов малого бизнеса. Но поддержки в таком формате оказалось недостаточно. В Республике Коми произошло снижение числа малых предприятий с 27,5 тыс. ед. в 2019 г. до 26 тыс. ед. в 2020 г. Численность занятых в сфере малого предпринимательства снизилась с 67 человек в 2019 г. до 65 человек в 2020 г. ${ }^{1}$

Причина такого положения заключается в отсутствии в стране отрегулированного, четко настроенного механизма государственной поддержки и доведения ее до сегмента малого предпринимательства. Решения, принятые на федеральном уровне, до них доходят довольно медленно, срок реализации программ государственной поддержки субъектов малого бизнеса лимитирован, заключен в узкие

\footnotetext{
${ }^{1}$ Предприниматели Коми получили поддержку. URL: https://komiinform.ru/news/206522/. (дата обращения: 22.02.2021). Текст: электронный.
} 
временные рамки. В итоге они не успевают к указанному сроку сформировать обязательный комплект документации для ходатайствования требуемой помощи. В этих условиях доминирующими являются стандартизация правил и формирование открытого реестра документов, необходимых для участия в проектах поддержки, оперативное доведение до субъектов малого бизнеса информации о таких программах. Проявляется неизбежность формирования экосистем на базе цифровых технологий для гарантированного получения предпринимателями всевозможных видов финансовой и нефинансовой помощи со стороны государственных институтов в принципиально новом онлайн-формате посредствам электронного документооборота и межведомственного взаимодействия в режиме «одного окна».

Неблагоприятные метаморфозы существующей социально-экономической конъюнктуры, обусловленные пандемией COVID-19, невозможно будет преодолеть быстро, последствия будут сказываться на продолжительном временном интервале, а испытания будут грозить всем хозяйствующим субъектам. При таком раскладе особенно важно не выносить необдуманные вердикты, направленные на обеспечение текущей социально-экономической стабильности. Целесообразно не акцентироваться на удовлетворении неотложных потребностей, а сконцентрировать внимание на реализации долгосрочной политики устойчивого восстановления экономики с учетом новой повестки дня.

Поэтому требуется введение региональными органами исполнительной власти практик поддержки бизнеса, которые строятся на принципиально новых управленческих подходах и которые могут применяться как во время восстановления, так и в последующие периоды.

\section{Литература}

1. Андреева О. В., Куринова Я. И., Суховеева А. А. Антикризисные меры государственной поддержки субъектов малого и среднего предпринимательства в современных экономических условиях, проблемы их реализации // Вестник Алтайской академии экономики и права. 2020. № 9. С. 5-11.

2. Бернстайн П. Фундаментальные идеи финансового мира: эволюция; перевод с английского. Москва: Альпина Бизнес Букс, 2009. 247 с.

3. Развитие малого и среднего предпринимательства как фактор ускорения экономического роста / А. П. Жабин, Е. В. Волкодавова, Г. И. Яковлев, Ю. О. Машина // Науковедение. 2017. № 4. С. 1-13.

4. Найденова Т. А., Новокшонова Е. Н. Антикризисные меры поддержки организаций малого и среднего предпринимательства в Республике Коми в период пандемии COVID-19 // Право, экономика и управление: от теории к практике: материалы всероссийской научно-практической конференции с международным участием (Чебоксары, 29 января 2021 г.) / редкол.: Э. В. Фомин [и др.] Чебоксары: Среда, 2021. С. 162-167. Текст: непосредственный.

5. Обухова Е. Имитация поддержки // Эксперт. 2020. № 15. URL: https://expert.ru/expert/2020/15/imitatsiya-podderzhki (дата обращения: 06.02.2021). Текст: электронный.

6. Рязанцева Н. В., Борель А. Э., Пащенко Ф. С. Направление взаимодействия с регионами // Аналитический бюллетень НИУ ВШЭ об экономических и социальных последствиях коронавируса в России и в мире. 2020. № 2. C. 91-103. URL: https://region.hse.ru/anti-crisis_2. (дата обращения: 06.02.2021). Текст: электронный. 
T. A. Найденова, E. Н. Новокшонова. Финансово-кредитные инструменты поддержки организаций малого бизнеса в Республике Коми в контексте COVID-19

7. Стиглиц Дж. Ю. Экономика государственного сектора: перевод с английского. Москва: Изд-во МГУ-ИНФРА-М, 1997.720 с. Текст: непосредственный.

8. Финансовые и денежно-кредитные методы регулирования экономики. Теория и практика / под редакцией М. А. Абрамовой, Л. И. Гончаренко, Е. В. Маркиной. Москва: Юрайт, 2014. 551 с. Текст: непосредственный.

9. Шопперт К. А., Юзвович Л. И. Финансово-кредитные инструменты государственной поддержки малого бизнеса // Фундаментальные исследования. 2019. № 10 . C. 123-128; URL: http://fundamental-research.ru/ru/article/view?id=42574 (дата обращения: 24.01.2021). Текст: электронный.

10. Щурина С. В. Меры поддержки субъектов малого и среднего предпринимательства в приоритетных отраслях российской экономики // Экономика. Налоги. Право. 2020. № 1. С. 60-71. Текст: непосредственный.

Статья поступила в редакцию 23.03.2021; одобрена после рецензирования 28.04.2021; принята к публикации 28.04.2021.

\section{FUNDING AND FINANCING INSTRUMENTS FOR SUPPORT OF SMALL BUSINESSES IN THE REPUBLIC OF KOMI UNDER COVID-19}

Tatyana A. Naydenova

Cand. Sci. (Econ.), A/Prof.

naydenovata@mail.ru

Elena N. Novokshonova

Cand. Sci. (Econ.), A/Prof.

einai@mail.ru

Pitirim Sorokin Syktyvkar State University

55 Oktyabrsky Prospect, Syktyvkar 167001, Russia

Abstract. Socio-economic changes caused by the COVID-19 pandemic are a significant challenge for the small business sector, which is experiencing a shortage of financial resources. In the conditions when traditional methods of support became insufficient, state authorities were forced to immediately change the existing approaches to small businesses support, and to introduce new measures for ensuring social and economic stability. The article is aimed at assessing the effectiveness of anti-pandemic funding and financing instruments for supporting small businesses in the conditions that have developed as a result of COVID crisis. It is concluded that regional events execution along with federal measures to support small businesses allowed reducing the negative consequences of COVID crisis. However, anti-crisis programs for financing and crediting small businesses are inadequate in scale to the needs of this economic segment.

Keywords: finance, funding and financing instruments, government support measures, small business, pandemic, development institutions

\section{For citation}

Naydenova T. A., Novokshonova E. N. Funding and Financing Instruments for Support of Small Businesses in the Republic of Komi under COVID-19. Bulletin of Buryat State University. Economy and Management. 2021; 2: 55-65 (In Russ.).

The article was submitted 23.03.2021; approved after reviewing 28.04.2021; accepted for publication 28.04.2021. 